UDC 631.365

\author{
Zykov A.V. ${ }^{1}$, Zakharov A.M. ${ }^{2}$, Junin V.A. ${ }^{3 \odot}$ \\ ${ }^{1}$ Researcher, ${ }^{2}$ Cand. Sc. (Engineering), ${ }^{3}$ Cand. Sc. (Engineering), \\ ${ }^{1,2,3}$ Institute for Engineering and Environmental Problems in Agricultural Production (IEEP) \\ branch of FSAC VIM, Saint Petersburg
}

\title{
PROCESS RESEARCH LOSS OF THE PRESSURE AIR DURING THE EXPANSION OF HAY IN ROLLS
}

\begin{abstract}
Questions of requirements to the quality of harvested hay in the process of the dried plant is a hot topic of modern agriculture. Therefore, in the article the process of loss of air pressure during the drying hay rolls is proposed to take into account the moisture absorption capacity in further research.

Аннотация

Вопросы требований к качеству заготавливаемого сена в проиессе досушивания растительной является актуальной темой современного сельского хозяйства. Поэтому в статье процесс потери давления воздуха при досушивании рулонов сена предлагаются учитывать влагопоглотительную способность при дальнейших исследованиях.
\end{abstract}

Keywords: final drying, dooshima mass diffusion plant, nutrients, process.

Ключевые слова: досушивание, досушиваемая массы, воздухораспределительная установка, питательные вещества, процесс.

Удельный вес сена в кормовом балансе довольно высок и практически остается стабильным при различных способах содержания животных. От его качества в значительной степени зависит эффективность производства животноводческой продукции. Качественное сено нормализует процессы пищеварения и снабжает организмы животных комплексом питательных веществ и витаминов, характерных для используемого зеленого сырья. Однако успех при его заготовке известными способами находится в большой зависимости от погодных условий.

Искусственное досушивание в сенохранилищах различного типа провяленной в поле травы практически не проводится, тем самым получение высококачественного сена определяется погодными условиями. Таким образом, необходимо проведение исследований, направленных на разработку интенсивной машинной технологии, включающей технические средства для консервации кормов, обеспечивающие адаптацию процесса досушивания к погодным условиям.

Удельный вес сена в кормовом балансе довольно высок и практически остается стабильным при различном содержании животных. От качества сена в значительной степени зависит эффективность производства животноводческой продукции. Однако успех при его заготовке известными способами находится в большой зависимости от климатических условий именно в процессе заготовки.

Особый интерес представляет заготовка сена рулонной технологией, которая внедрена практически во все сельскохозяйственных предприятиях Северо-Западного региона РФ.

Эта технология имеет целый ряд преимуществ, так как крупные рулоны обладают большой массой и противостоят проникновению влаги во внутрь рулона это способствует лучшей сохранности питательных веществ и повышении качества сена. Применение ее позволяет механизировать все технологические операции от заготовки и раздачи сена на

\footnotetext{
${ }^{\circledR}$ Zykov A.V., Zakharov A.M., Junin V.A., 2019
} 
фермах. Однако, существующие в переувлажненной осадками Северо-Западной зоне, интенсивные технологии заготовки сена связаны с уборкой провяленной травы с поля с последующей досушкой ее способом принудительного вентилирования в стационарных установках.

Проведенные исследования указывают на то, что полностью досушить спрессованную в крупногабаритные рулоны провяленную траву на имеющихся сушильных установках без значительных энергозатрат и потерь качества получаемого корма не представляется возможным. Поэтому требуется разработать и внедрить специализированное индивидуально-групповое оборудование для форсированной сушки рулонов провяленной травы.

Для обоснования выбора технических параметров и режимов работы оборудования, обеспечивающих получение высококачественного прессованного в рулоны сена при меньших затратах энергии на процесс сушки, важно иметь представление об аэродинамических показателях обрабатываемого материала.

Досушиваемый рулон сена представляет собой систему с весьма сложными и многообразными геометрическими характеристиками. Формы и размеры пустот внутри рулона очень сложны и разнообразны. Способность воздуха перемещаться в таких каналах не одинакова по различным направлениям. Поэтому целесообразно вводить некоторые обобщенные характеристики. Основными из них являются: пористость и эквивалентный диаметр.

Пористость или доля свободного объема выражает свободное пространство между частями в единице объема материала. Для анализа пористости уложенного растительного сырья пользовались методом испарения всей влаги, находящейся в поровых каналах материала и по массе испарившейся влаги, определяли объем пор. Такой подход нередко не справедлив потому, что влагомолекулярная адсорбция в процессе сушки не испаряется. Но этой ошибкой можно пренебречь и формально принять ее за основу расчета концентрации влаги в любой форме связи.

Ранее проведенные исследования по определению пористости слоя прессованной

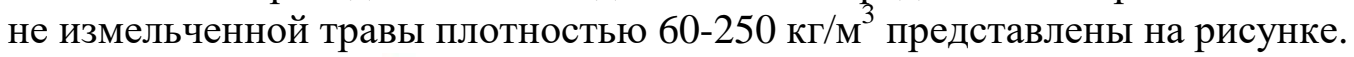

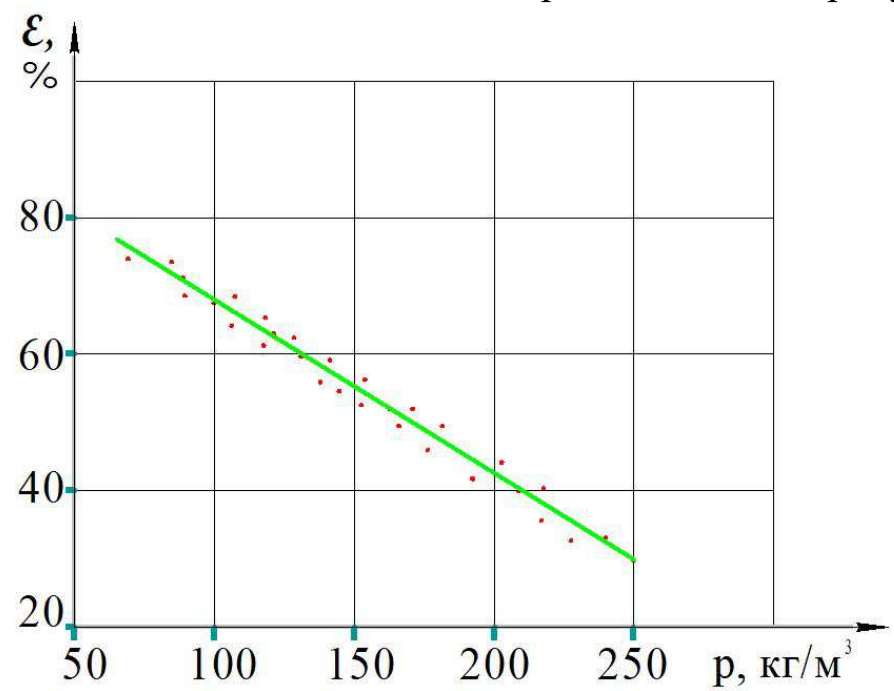

Рисунок 1 Зависимость пористости рулонов (тюков) травы ( $\mathcal{E}$ ) от плотности прессования $(\rho)$.

Полученные результаты можно аппроксимировать в эмпирическую формулу

$$
\varepsilon=96-0,25 \rho_{\text {сл }},
$$

где $\rho_{\text {сл }}-$ плотность прессования материала, кг/м². 
Аналогичные результаты получены Любарским В.М. [1] и Деркачевым И.П. [2]. В их исследованиях пористость уложенного плотностью 50-140 кг/м ${ }^{3}$ сена, определялась по методике профессора Дейка К.П., заполняя пустоты предварительно сжатым воздухом и заливая образцы бензолом. Полученные данные показывают, что пористость уложенной травы не зависит от формы частиц, состояния их поверхности, а зависит только от характера упаковки, т.е. от плотности прессования.

Частицы растений обладают и внутренней пористостью. Внутренняя поверхность и объем пор, имеющихся в стеблях растений, существенно определяют их статику (емкость) и кинетику (адсорбцию). В этих порах практически нет гидродинамических потоков. Поэтому в величину, характеризующую гидродинамические свойства в слое, не включается внутренняя пористость.

Наиболее характерным определяющим размером стационарного слоя (тела рулона) является эквивалентный диаметр. Он объединяет два основных параметра - пористость материала и удельную поверхность частиц досушиваемой травы:

$$
d_{\ni}=\frac{4 \varepsilon}{S}=\frac{4 \varepsilon}{S_{0}(1-\varepsilon)},
$$

где $S$ - поверхность частиц слоя, приходящаяся на единицу его объема, $\mathrm{m}^{2} / \mathrm{m}^{3}$;

$S_{0}$ - удельная поверхность частиц материала, м $^{2} / \mathrm{m}^{3}$.

Эквивалентный диаметр соответствует суммарному поперечному сечению каналов в слое материала, обычно его определяют экспериментальным путем. Опыты, проведенные при обработке слоев плющенной провяленной [3], измельченной [4], не измельченной [5] травы показывают, что эквивалентный диаметр (без учета пустот внутри стеблей) в основном зависит от плотности укладки травы в слое и выражается формулой:

$$
d_{\ni}=0,66 \rho_{c}^{-1,35}
$$

При расчете системы вентиляции сушильной установки нужно найти сопротивление определенных ее частиц движению воздуха, которое в определенных ситуациях влияет не только на выбор вентилятора, но также и на тип сушильной установки и ее рабочий процесс. Как известно, статическое давление, которое создает вентилятор при досушивании слоя провяленной травы, используется на потери давления воздуха в слое материала, преодоление трений и местных сопротивлений воздухораспределительной системы. Потери давления на преодоление трения и местных сопротивлений в воздухораспределительной системе вентиляционного оборудования, по сравнению с потерями давления в слое, незначительны и составляют всего около 5\% $[6,7,8]$.

Теоретическим определением этих потерь занимаются давно. Однако число аналитических решенных случаев в настоящее время не велико. Объясняется это тем, что до сих пор не разработан общий аналитический метод расчета сопротивлений в слое. Привлекаемые для решения этой задачи уравнения аэродинамики, как правило, нуждаются в тех или иных допущениях. Явление целом усложняет то, что поры в слое имеют различные формы, и частицы воздуха при своем движении изменяют направление и удлиняют путь передвижения. В результате решение получается приближенным.

Вследствие этого определить потери давления в слое досушиваемого материала возможно экспериментальным путем используя при этом зависимость, аналогичную по виду уравнению для определения потерь давления на трение в шероховатых трубопроводах.

$$
\Delta P=\lambda_{\ni} \frac{H \rho_{B} v^{2}}{2 d_{\ni}},
$$


где $\lambda_{\ni}$ - общий коэффициент сопротивления, который учитывает влияние сопротивления трения и дополнительные местные сопротивления, возникающие при движении воздуха по искусственным каналам в слое и обтекание его отдельных элементов, т.е. является общим коэффициентом сопротивления;

$H$ - толщина досушиваемого слоя, м;

$\rho_{\boldsymbol{B}}-$ плотность вентилируемого воздуха, кг/м ${ }^{3}$;

$v$ - скорость движения воздуха через слой материала, м/с.

Общий коэффициент сопротивления зависит от аэродинамического режима, определяемого значением критерия Рейнольдса. Для плотного слоя провяленной травы, обобщив экспериментальные данные, полученные при досушивании рассыпной, прессованной травы [5], мы получили следующую формулу для определении $\lambda_{\ni}$ :

$$
\lambda_{\ni}=\frac{641,3}{R_{e}^{1.18}}
$$

где $R_{e}$ - число Рейнольдса.

Используя формулы $(3,4,5)$, с учетом потерь в воздухораспределительной системе воздухораспределительного оборудования можно определить давление, потребляемое для поддержания заданной скорости воздуха через материал при вентиляции.

Мощность вентилятора, необходимая для преодоления сопротивления матариала и воздуховода при перемещении воздуха через слой определяют по формуле:

$$
N=\frac{\kappa_{3} L \Delta P}{1000 \eta},
$$

где $\kappa_{3}-$ коэффициент запаса, учитывающий сопротивление воздушной системы и утечка воздуха (к $=1,2 \ldots 1,4)$

$\Delta P$ - потери давления в слое, $\mathrm{H} / \mathrm{M}^{2}$;

$\eta$ - к.п.д. вентилятора $(\boldsymbol{\eta}=0,85 \ldots 0,90)$

Из вышеизложенного следует, что поскольку на сушку поступают рулоны определенной плотности, то уменьшение потерь давления, а значит и расход электроэнергии на привод вентилятора достигается за счет снижения скорости движения воздуха через рулон. А для сохранения производительности оборудования при заготовке качественного сена необходимо повысить влагопоглотительную способность вентилируемого воздуха, что может быть достигнуто его предварительным нагревом.

\section{References:}

1. Любарский В.М. Исследование процесса досушивания измельченного сена в слое методом активного вентилирования в условиях Литовской ССР: Автореферат на соискание уч. степени канд. техн. наук. / В.М. Любарский Каунас, 1969. 19 с

2. Деркачев И.П. Исследование процесса досушивания плющенного сена активным вентилированием в условиях Северного Кавказа: Автореферат на соискание уч. степени канд. техн. наук. / И.П. Деркачев Ставрополь, 1973. 19 с

3. Кузнецов Н.Н. Повышение эффективности заготовки прессованного в рулоны сена путем оптимизации параметров процесса сушки и режимов работы оборудования: автореф. дис. на соискание ученой степени канд. техн. наук: 05.20.0 1/ Н.Н. Кузнецов. Санкт-Петербург, 2007. 17 с.

4. Зыков А.В. Эффективность применения химических консервантов при заготовке кормов трав, прессованных в рулоны / А.В. Зыков., В.А. Юнин., А.М. Захаров. // 
Технологии и технические средства механизированного производства продукции растениеводства и животноводства. 2018. № 96. С. 138-145.

5. Попов В.Д. Основы управления технологиями низкотемпературной сушки растительной стебельчатой массы / В.Д. Попов., М.Ш. Ахмедов, А.И. Сухопаров, Н.Н. Кузнецов, А.В. Зыков. // Санкт-Петербург: ИАЭП, 2017. -142 с.

6. Сечкин В.С. Технико-технологическое обеспечение заготовки кормов из трав при повышенном увлажнении / В.С. Сечкин., А.И. Сухопаров., М.Ш. Ахмедов. // Механизация и электрификация сельского хозяйства. 2012. № 3. С. 22-25.

7. Сухопаров А.И. Научное обеспечение машинных технологий заготовки сена в условиях Северо-Запада России / А.И. Сухопаров / Сборник научных докладов ВИМ. 2011. Т. 1. С. 357-362.

8. Попов В.Д. Исследование сушки прессованной в рулоны провяленной травы / В.Д. Попов., Н.Н. Кузнецов. // Техника в сельском хозяйстве. 2007. №6. С. 47-49. 